ENCYCLOPEDDIE Encyclopédie berbère

BERBERE

3 | 1986

3 | Ahaggar - Alī ben Ghaniya

\title{
Akuš (Yakūš/Yuš)
}

\section{G. Camps et S. Chaker}

\section{OpenEdition}

Journals

Édition électronique

URL : http://journals.openedition.org/encyclopedieberbere/2406

DOI : 10.4000/encyclopedieberbere.2406

ISSN : 2262-7197

\section{Éditeur}

Peeters Publishers

\section{Édition imprimée}

Date de publication : 1 juillet 1986

Pagination : 431-432

ISBN : 2-85744-260-2

ISSN : 1015-7344

\section{Référence électronique}

G. Camps et S. Chaker, "Akuš (Yakūš/Yuš) », Encyclopédie berbère [En ligne], $3 \mid$ 1986, document A152, mis en ligne le 01 décembre 2012, consulté le 13 octobre 2020. URL : http://journals.openedition.org/ encyclopedieberbere/2406; DOI : https://doi.org/10.4000/encyclopedieberbere.2406

Ce document a été généré automatiquement le 13 octobre 2020

(c) Tous droits réservés 


\section{Akuš (Yakūš/Yuš)}

\section{G. Camps et S. Chaker}

1 Nom de Dieu chez les Berbères d'après une phrase de la Cronique d'Abū Zakariyyā': «L'imam (Abd el Wāhhāb), Dieu l'agrée, leur envoya une lettre où il leur ordonnait de le (Abū'Ubaïda) prendre pour gouverneur et leur faisait ce serment : Par Allāh en arabe, par Radīr en langage citadin, par Akuch en berbère, par lzā en abyssin, je ne confierai les affaires des Musulmans qu'à l'homme qui dit " je ne suis qu'un pauvre homme " (trad. Le Tourneau, Rev. afric., t. CIV, 1960, p. 163).

2 Il s'agit du même mot que Yakūs* que les Barghwata* substituaient, dans la prière, à celui d'Allah (El Bekri, Description de l'Afrique, trad. de Slane, Maisonneuve, 1965, p. 267). Ce nom est cité sous cette forme dans le Kitab et Tabaqet de Jarjini à propos d'une consultation du Cheikh Abū 'Ammar ben Abi Ya'qūb qui vivait à Ouargla au vi siècle de l'Hégire.

3 Une forme voisine Yuš se rencontre dans la Mudawwana d'Ibn Ghanem de Djerba et dans une chronique anonyme ibadite publiée par T. Lewicki (Rev. des Et. islam., III, p. 275-279) et, au Mzab, dans des formules incantatoires pour obtenir la pluie.

4 Seul le Bayān el Moghrib d'Ibn el Idhari donne la forme Bakuš qui a servi d'argument pour rattacher ce nom divin à celui du dieu Bacchus. Cette forme est certainement due à une erreur de lecture ou à un défaut du manuscrit car en arabe $\mathrm{B}$ et $\mathrm{Y}$ ne se distinguent que par le nombre de points diacritiques (B: $:$, Y Y). G. Marcy fait dériver Yakūš du nom de Jésus. Le rapprochement, dans le serment d'Abd el Wāhhāb, de Akouch en berbère et de Izā (Jesús) en abyssin, aurait pu être un argument supplémentaire en faveur de cette hypothèse irrecevable. Les nombreux auteurs (M. C. de Slane, A. de Motylinski, R. Basset, G. Marcy) qui ont tenté d'expliquer ce nom n'ont retenu que les formes Yakūš et Yuš et non celle de Akuš qui n'est peut-être qu'une contraction.

Yakūš et Yuš sont sans doute deux formes dialectales d'un même nom et il s'agit très certainement d'un radical verbal précédé de la marque personnelle de $3^{\text {ème }}$ personne de masculin singulier $y$ («il»). Le verbe, encore bien attesté dans les parlers berbères modernes (Maroc, Chaouïa, Mzab) sous la forme aš/uš, a le sens de «donner ». L'autre forme du verbe ${ }^{*}(a) k(u) \check{s}$, bien que non attestée en tant que verbe, se perpétue 
néanmoins en kabyle ou il existe un terme tukši/tikši, signifiant «don » et qui dérive d'un radical *kš.

6 Le nom de Dieu en berbère signifiait donc vraisemblablement «il a donné ", « il donne».

\section{BIBLIOGRAPHIE}

ABU ZAKARIYYĀ'Al WARGALANI. Chronique. Trad. Le Tourneau, Rev. Afric, t. CIV, 1960, p. $99-176$ et 322-390, t. CV, 1961, p. 117-176. II ème partie trad. R. Idris, t. CV, 1961, p. 323-374 et t. CVI, 1962 , p. 119-162.

CALASSANTI-C. MOTYLINSKI, A. de. Le nom berbère de Dieu chez les Abadhites. Alger, 1905.

BASSET R. Recherches sur la religion des Berbères. Rev. de l'Hist. des Relig., 1910, t. LXI, p. 316

MARCY G. Le Dieu des Abadites et des Berg்wata.- Hespéris, t.XXII, 1936, p. 33-56.

LEWICKI T. Sur le nom de dieu chez les Berbères médiévaux. Folia orientalia, t.VIII, 1967, p. 228.

INDEX

Mots-clés : Linguistique 